\title{
THE VARIABILITY OF INTERLANGUAGE USE
}

\author{
Yasmine Kilian, Port Elizabeth Technikon
}

\section{INTRODUCTION}

One area of interest in research into second language (L2) acquisition is the nature and properties of the L2 learner's developing knowledge of the target L2 grammar. Variability is evident in the interlanguage grammars of all L2 learners, irrespective of their levels of proficiency; their interlanguage use is characterised by the variable occurrence of target L2 forms, and the occurrence of more than one variant of a form where the target L2 has only one. This pattern of linguistic behaviour is called "non-systematic variability". In this article, the phenomenon of this variability in L2 knowledge is investigated.

The existing body of knowledge about L2 acquisition provides ample proof that L2 learners are characteristically variable in their interlanguage use. The question arises, however, as to why the learners' interlanguage grammars exhibit this variability. In this article, I attempt to answer this question. In brief, it appears that non-systematic variability results from the way in which mental systems involved in the construction of interlanguage grammars interact with different types of linguistic input. The linguistic input to which L2 learners are exposed differs from that to which first language (L1) learners are exposed (Towell and Hawkins 1994:155, 160). In addition to naturally occurring sentences of the target L2, L2 learners typically receive explicit instruction and negative feedback. These different kinds of linguistic input are processed by different mental systems and give rise to different kinds of interlanguage knowledge. According to Towell and Hawkins (1994:182), a learner who receives explicit instruction and negative feedback acquires "learned linguistic knowledge which enables him or her to behave in one context as if the parameter has been reset. The result may produce the kind of behaviour which has been called non-systematic variability".

In order to arrive at an understanding of interlanguage variability, I will, firstly, examine the different types of knowledge systems which underlie linguistic behaviour. Secondly, I will 
look at the kinds of linguistic input which give rise to the different knowledge systems. Finally, I will present an explanation for non-systematic variability based on the findings of four studies on L2 acquisition, namely (Felix and Weigl 1991), (White 1991), (Doughty 1991) and (White, Spada, Lightbown, and Ranta 1991).

\section{LINGUISTIC KNOWLEDGE SYSTEMS}

Two different knowledge systems, namely competence and learned linguistic knowledge (LLK), are believed to underlie an L2 learner's linguistic behaviour. Krashen points out the difference between competence and LLK, using the terms "acquired knowledge" and "learned knowledge" to refer to competence and LLK, respectively (cf., for instance, Krashen 1985:1, 1994:45). This distinction between competence and LLK is endorsed by Schwartz (1993:51), who relates competence to Universal Grammar (UG)-based knowledge and LLK to non-UG based knowledge.

According to Krashen, acquired knowledge results from the subconscious process of language acquisition and, as a result, the language user is not consciously aware of the rules of the language s/he is using (Gass and Selinker1994:144). On Schwartz's (1993:51, 150) view, competence is innate (because UG is innate) and forms part of a unique language-specific cognitive system.

Krashen considers learned knowledge to be conscious knowledge (Gass and Selinker 1994:144). When a language user has learned knowledge of a language, s/he knows the rules, is aware of them and is able to talk about them (ibid). Unlike competence, LLK is created via the central processing systems (Schwartz 1993:157). However, both competence and LLK affect fluency and accuracy of language production (Towell and Hawkins 1994:174).

Competence and LLK are unobservable and have to be inferred from observable behaviour (Schwartz 1993:150). Competence and LLK each underlie a distinct type of L2 linguistic behaviour (ibid). Linguistic behaviour stemming from competence is called "performance", whereas linguistic behaviour which stems from LLK is called "learned linguistic behaviour" (LLB) (ibid). 
Towell and Hawkins (1994:175) point out that it may be difficult to distinguish performance from LLB. However, researchers should be able to tell the difference if they can determine whether the linguistic behaviour stems from knowledge that was acquired or from knowledge that was learnt.

\section{TYPES OF LINGUISTIC INPUT}

In this section, the kinds of linguistic input that respectively give rise to competence and LLK, the two different knowledge systems underlying L2 linguistic behaviour, will be discussed. The role that each kind of input is claimed to play in L2 acquisition, according to Schwartz and Krashen, will then be discussed.

According to Schwartz (1993:148), a learner's knowledge system of a particular language can grow only if that learner is exposed to utterances of the language. This kind of linguistic input is called "primary linguistic data" (PLD) by Schwartz (1993:148) and "comprehensible input" by Krashen (1985:2-3). A learner uses PLD to generate hypotheses about the knowledge system underlying the L2 (Schwartz 1993:148). The learner's resulting knowledge system is Schwartz's UG-based competence and Krashen's acquired knowledge.

Other types of linguistic data, i.e. other than PLD, are called "non-primary linguistic data" (non-PLD). Non-PLD can take the form of information about what is not possible in a particular language. Such information is obtained through correction and negative feedback. Another example of non-PLD is explicit instruction, or explicit data, received during formal (explicit) learning of the language (Gass and Selinker 1994:144). Non-PLD give rise to Schwartz's LLK and Krashen's learned knowledge.

\section{THE EFFECT, IF ANY, OF NON-PLD ON L2 COMPETENCE}

Can explicit instruction and negative feedback affect interlanguage competence? In this section, I will explain why this question arises. In order to do so, I will, firstly, relate Krashen and Schwartz's views on the effects of different kinds of input to a modular view of the 
human mind. Secondly, I will explain why, in certain circumstances, L2 learners need explicit instruction and negative feedback to discover that their hypotheses about the L2 are incorrect.

\subsection{Krashen's view}

Krashen (1994:45) views acquired knowledge and learned knowledge as being internalised differently. Furthermore, Krashen states that learned knowledge can never become acquired knowledge (Gass and Selinker 1994:145). It is evident, therefore, that, on Krashen's view, (i) the knowledge system derived from PLD is distinct from that which is derived from non-PLD and (ii) non-PLD cannot affect competence. Krashen's views are consistent with a modular view of the human mind. According to Le Roux (1994:25), a modular view of the mind implies that acquired knowledge is part of the language module while learned knowledge is stored in the central systems. The central systems can read information produced by the language module. However, the language module cannot read information, such as learned knowledge, which is stored in the central systems (ibid).

\subsection{Schwartz's view}

Krashen's views on modularity are shared by Schwartz. Schwartz (1993:157) claims that only PLD can feed into the language module, based on the fact that L1 grammars are built on PLD only (ibid). According to Schwartz (1993:157-8), negative feedback and explicit instruction serve only to give the L2 learner knowledge about language, not knowledge of language (i.e., not competence). Schwartz (1993:157) argues that knowledge about language is computed and stored in the central systems and cannot be read by the language module. Therefore, nonPLD (that leads to knowledge about language) cannot affect competence (that is stored in the language module).

\subsection{The role of non-PLD in $\mathrm{L} 2$ acquisition}

In contrast to Krashen's and Schwartz's claims, White (1989) proposes that, in addition to PLD, learners also need non-PLD in order to arrive at the correct hypotheses about the L2 (cf. Le Roux 1994:23). Non-PLD are considered to be necessary when the L2 input to which the 
learner is exposed is either (i) not target-like or (ii) does not provide evidence of what is not possible in the L2 (ibid). An example of the former is when the bulk of the L2 input is provided by other L2 learners of the same target L2. This is the case when L1 speakers of English learn Afrikaans as L2 from other L2 speakers of Afrikaans whose L1 is English. These L2 learners are exposed to a large quantity of non-target-like L2 input. For example, the learners will receive as input sentences such as *Hy dink dat hy het haar gesien (= He thinks that he has her seen) instead of Hy dink dat hy haar gesien het (=He thinks that he her seen has). As a result, these learners may fail to invert subject and verb after the complementiser dat (=that). In this case, they will need explicit instruction to acquire the correct target L2 form. Negative evidence becomes pertinent in (ii) above. To illustrate this point, consider the example of a L1 speaker of Afrikaans learning English. Afrikaans permits the placement of an adverb between a verb and its direct object, whereas English does not. Therefore, the L1 speaker of Afrikaans needs evidence that sentences such as *He eats quickly his food are not permitted in English.

Having established that knowledge of some aspects of the L2 can be arrived at only via nonPLD, and bearing in mind Krashen's (and Schwartz's) distinction between acquired and learned knowledge, L2 acquisition researchers have begun to enquire whether such knowledge can indeed affect competence (Le Roux 1994:24).

\section{THE LINK BETWEEN APPARENT PARAMETER RESETTING AND NON- SYSTEMATIC VARIABILITY}

In the following section, four studies, viz. (Felix and Weigl 1991), (White 1991), (Doughty 1991) and (White et al. 1991), are discussed. The results of these studies shed some light on the question of whether or not non-PLD can effect L2 acquisition. Their findings point to the fact that the learners behaved in one context "as if the parameter had been reset" and that apparent (as opposed to actual) parameter resetting "may produce the kind of behaviour which has been called nonsystematic variability" (Towell and Hawkins 1994:182). 


\subsection{Parameter resetting}

Linguistic parameters are a feature of UG. According to Radford (1997:16), UG theory, developed by Noam Chomsky, posits the existence of a universal set of innately endowed principles of grammar which determine the nature of grammatical structure in natural languages. It is accepted that every principle has a limited number of parameters, where "parameter" refers to one of the possibilities left open by the principle, from which specific languages may choose (Waher 1991:4). In the process of L1 acquisition, a child acquires competence by selecting values for the parameters on the basis of PLD that $\mathrm{s} /$ he is exposed to (Cook \& Newson 1996:79). According to some researchers (cf. Le Roux 1994:24, White 1985), it follows, therefore, that when the same child acquires an L2, s/he will have to reset the parameters to the correct target L2 values. Upon setting the new parameter value, the learner will end up with knowledge of other grammatical properties associated with the value of the parameter "for which no known (direct) PLD exist" (Schwartz 1993:154-5). This is so because parameters are associated with clusters of related grammatical properties, the knowledge of which is triggered once the value of the parameter has been set (Gass and Selinker 1994:128). When a French-speaking child, for instance, sets the verb movement parameter to [+ verb movement] on the basis of exposure to French sentences containing adverbs, the child should end up knowing (in the absence of direct PLD) that verb movement also applies to negatives and questions (White 1991:341).

\subsection{The studies}

The findings of the studies below indicate that non-PLD have an immediate positive effect on the linguistic behaviour of the subjects.

\subsubsection{Felix and Weigl (1991)}

This study focused on the acquisition of English as an L2 by 77 German-speaking high school students. The students were exposed to and learnt English in the classroom predominantly, through instruction from non-native speakers of English. 
Three groups of students, representing beginning, intermediate and advanced learners, were tested for their ability to correctly judge UG-based grammaticality contrasts in English. These contrasts did not involve structural properties which are learnable on the basis of PLD, did not share similarities with L1 structures and were not explicitly taught in the classroom.

The test results were very poor. Out of a total of 60 sentences, only one sixth were judged correctly by approximately $45 \%$ of the learners. Not only was no significant difference evident in the results of the three groups, the learners also appeared to have systematically given the wrong answer. A detailed analysis of the learners' responses revealed that they employed two main strategies, namely (i) they assumed that what was permitted in the L1 was also permitted in the L2 and (ii) they refused to generalise beyond what had been taught.

\subsubsection{White (1991)}

This study investigated the effects of positive and negative evidence on L2 acquisition. In particular, White focused on the acquisition of English adverbs by 11 and 12 year old Frenchspeaking learners. These learners were beginners, whose exposure to English was limited to approximately two hours of instruction per week.

Francophone learners of English, whose L1 instantiates the subject-verb-adverb-object (SVAO) order, have to learn that this word order is incorrect in English. Furthermore, they have to acquire the SAV order for English, which is incorrect in French. According to White (1991:138), the SAV order can be learnt on the basis of positive evidence. SVAO sentences, however, do not occur in English. Thus, there is no positive evidence that such sentences are ungrammatical. For this reason, it was hypothesised that L2 learners would require negative evidence in order not to produce SVAO sentences in English.

Learners were assigned to two experimental groups. One group received instruction on English adverb placement, whereas the other group was given instruction on question formation instead of adverbs. Instruction on question formation aimed at familiarising the subjects with the activities used to test knowledge of adverbs. A comparison group consisted of 10 and 11 year old monolingual L1 speakers of English. The research design involved a 
written pre-test, a period of instruction, two written post-tests, five weeks apart, and a written follow-up test one year later.

The results indicated that only those learners who were instructed on adverb placement came to know that SVAO is not an accepted English word order. This knowledge was not lost in the period between the two post-tests. However, the follow-up test revealed that the instructed learners did not retain their new knowledge.

\subsubsection{Doughty (1991)}

Doughty investigated the effects of instruction on the acquisition of relativisation in the L2. The subjects were 20 international students at the intermediate level of English L2 proficiency. All the subjects arrived in the US with a background of instruction in English as a foreign language and had little knowledge of English relative clauses. However, they were considered ready to acquire relativisation on the basis of their performance on a level identification test.

The study involved a pre-test, a treatment period, and a post-test administered to two experimental groups and one control group. The experimental groups received exposure to and instruction in relativisation, while the control group was limited to exposure only. The tests contained both written and oral measures.

The learners' pre-instruction knowledge of relativisation was fairly similar and all groups showed an improvement on the post-test. However, the experimental groups improved twice as much as the control group. Furthermore, the instructed learners were able to generalise their new knowledge to other contexts of relativisation - a phenomenon not unlike that of generalising within a parameter (Towell and Hawkins 1994:178).

\subsubsection{White, Spada, Lightbown and Ranta (1991)}

White et al. investigated the effect of explicit teaching and corrective feedback on L2 learner's acquisition of English questions. The subjects were 10 to 12 year old French-speaking students who were beginner level English L2 learners. 
The study, which was conducted in two phases, employed two experimental groups. One group received instruction on question formation (the instructed group), while the second group was instructed on adverb placement (the uninstructed group). However, both groups were tested on their knowledge of questions. The first phase of the study consisted of a twoweek period. During the first week of this period, the subjects received three hours of instruction and, during the second week, two hours of follow-up activities. The results of a written post-test showed that explicit instruction had a positive effect on the subjects' knowledge of English questions in that the instructed group significantly outperformed the uninstructed group.

Phase 2 involved two experimental groups, namely an instructed group, which received instruction on English questions and an uninstructed group, instructed on English adverbs, as well as a comparison group of monolingual English speakers of the same age. Four and a half hours of instruction on question formation was given in the first week of a two-week period. In the second week, the learners spent four hours on follow-up activities. The learners' knowledge of questions was tested on a pre-test, a post-test (on the first day after instruction has ended) and a follow-up test (five weeks later). The tests consisted of two written tasks and an oral production task. The results of the written tasks show that the instructed group showed far greater improvement than did the uninstructed group, although neither group performed at native speaker levels. The positive effect of instruction was also reflected in performance on the oral task. However, the learners still accepted incorrect forms in the written test, and produced both correct and incorrect forms in the oral task. The positive results of the post-test were duplicated in the follow-up test 5 weeks later.

\subsection{Non-systematic variability}

The behaviour of the subjects in the discussed studies can be labelled "non-systematically variable behaviour". Non-systematically variable behaviour is the apparently interchangeable use of two or more variants of a grammatical property in a given context under the same conditions (Towell and Hawkins 1994:144). An example of this kind of behaviour is where a L1 speaker of Xhosa, during the course of the same conversation held in English, uses the pronouns he and she interchangeably when referring to a female. In the context of the post- 
tests in the studies, where conditions were stable, the learners used one variant in correctly reproducing the forms that had been taught. They used another variant in cases where they were unable to generalise their new knowledge to novel contexts.

Non-systematically variable behaviour can be viewed as a consequence of apparent parameter resetting. The learners in the studies acquired knowledge about the target L2. This LLK was stored in long-term memory. Towell and Hawkins (1994:164-5) point out that long-term memory is associated with automatic processes and that language becomes automatised only when familiarity is achieved. One can therefore assume that, as a result of exposure to nonPLD, the learners were sufficiently familiar with the relevant L2 forms to produce them automatically. This appears to have been the case in the context of the (written) post-tests. In reproducing their new knowledge correctly, the learners gave the impression of having reset the relevant parameters. Actual parameter resetting could, however, not have occurred, because the learners in (Felix and Weigl 1991) were unable to generalise their new knowledge. Also, in (White 1991) it was shown that parameter resetting had not occurred because the positive effect of non-PLD was not long term (Towell and Hawkins 1994:181). Finally, the results of neither (Doughty 1991) nor (White et al. 1991) constitute conclusive proof of parameter resetting because (i) there were no tests for long-term effects and (ii) in the case of (Doughty 1991), the language forms were not elicited in spontaneous speech. Because actual parameter resetting had not taken place, one can conclude that the learners produced forms which derived either from LLK or from the L1 parameter setting (Towell and Hawkins 1994:199). As can be seen in the studies, these two forms appear to be in "free" or nonsystematic variation in the learners' L2 production (ibid).

\subsection{Conclusion}

It would appear that Towell and Hawkins are correct in claiming that learners who receive explicit instruction and negative feedback merely behave "as if" the parameter has been reset. The results of the studies indicate that although non-PLD can modify learner language, it cannot affect competence. These findings appear to confirm Krashen's and Schwartz's modular view of the human mind. This does not, however, mean that L2 learning is doomed to failure. As Schwartz $(1993: 160)$ points out, even though non-PLD cannot affect 
competence, it can affect (learned) linguistic behaviour and that "sometimes that may be all we are seeking." In other words, by virtue of LLB, the learner is able to produce utterances which appear to be governed by the L2 parameter setting (that is, native-like utterances), as did the learners in the studies.

\section{SUMMARY}

Interlanguage variability has been shown to result from the way in which mental systems involved in the construction of interlanguage grammars interact with different types of linguistic input. L2 learners are exposed to both PLD and non-PLD. The latter is considered necessary when PLD alone cannot guarantee the generation of correct hypotheses about the target L2. However, the studies on L2 acquisition reviewed above show that non-PLD can give rise only to LLK and cannot affect competence (i.e. cannot bring about parameter resetting). LLK (expressed as LLB) enables learners to give the appearance of producing native-like speech. However, in the absence of genuine parameter resetting, the learners may (i) produce language forms which derive from either LLK or from the L1 and (ii) use these forms apparently interchangeably in a given context under the same conditions. This kind of linguistic behaviour, known as "non-systematic variability", frequently characterises the interlanguage grammars of L2 learners.

Acknowledgement: This article is a substantially revised version of part of an assignment submitted to the Department of General Linguistics at Stellenbosch University in 2001 in partial fulfilment of the requirements for the MPhil Programme in General Linguistics. I wish to acknowledge the contribution of the Department and, in particular, that of Mrs Southwood in supervising the work from which this article resulted. 


\section{REFERENCES}

Cook, V. and M. Newson. 1996. Chomsky's Universal Grammar. Oxford: John Blackwell Publishers.

Doughty, C. 1991. Second language instruction does make a difference. Studies in Second Language Acquisition 13: 431-469.

Felix, S.W. and W. Weigl. 1991. Universal Grammar in the classroom: the effects of formal instruction on second language acquisition. Second Language Research 7(2): 162-181.

Gass, S.M. and L. Selinker. 1994. Second language acquisition. An introduction. Hillsdale, N.J., etc.: Lawrence Erlbaum Associates.

Krashen, S.D. 1985. The Input Hypothesis: Issues and implications. London and New York: Longman.

Krashen, S.D. 1994. The input hypothesis and its rivals. In N.C. Ellis (ed.) 1994. Implicit and explicit learning of languages. London and New York: Academic Press. p. 45-77.

Le Roux, C. 1994. Modular minds and input in second language acquisition. SPIL PLUS 26: 17-35.

Radford, A. 1997. Syntactic theory and the structure of English. Cambridge, UK: Cambridge University Press.

Schwartz, B.1993. On explicit and negative data affecting and affecting competence and linguistic behaviour. Studies in second language acquisition 15: 147-163.

Towell, R. and R. Hawkins. 1994. Approaches to second language acquisition. Clevedon: Multilingual Matters.

Waher, H. 1991. Oor grense, kettings, en lisensies. 'n Sleutel tot Chomsky se teorie van grammatika [On boundaries, chains, and licences. A key to Chomsky's theory of grammar]. SPIL PLUS 16.

White, L. 1989. Universal Grammar and second language acquisition. Amsterdam: John Benjamins Publishing Company.

White, L. 1991. Adverb placement in second language acquisition: some effects of positive and negative evidence in the classroom. Second Language Research 7(2): 133-161.

White, L., N. Spada, P.M. Lightbown, and L. Ranta. 1991. Input enhancement and L2 question formation. Applied Linguistics 12(4): 416-432. 
White, L. 1985. The pro-drop parameter in adult second language acquisition. Language Learning 35: 47-62. 